\title{
Active faults crossing trunk pipeline routes: some important steps to avoid disaster
}

\author{
V. M. Besstrashnov ${ }^{1}$ and A. L. Strom ${ }^{1,2}$ \\ ${ }^{1}$ Geodynamic Research Center, LTD, Moscow, Russia \\ ${ }^{2}$ Institute of Geospheres Dynamics of Russian Academy of Sciences, Moscow, Russia
}

Received: 11 February 2011 - Revised: 22 March 2011

\begin{abstract}
Assessment of seismic strong motion hazard produced by earthquakes originating within causative fault zones allows rather low accuracy of localisation of these structures that can be provided by indirect evidence of fault activity. In contrast, the relevant accuracy of localisation and characterisation of active faults, capable of surface rupturing, can be achieved solely by the use of direct evidence of fault activity. This differentiation requires strict definition of what can be classified as "active fault" and the normalisation of methods used for identification and localisation of active faults crossing oil and natural gas trunk pipelines.
\end{abstract}

\section{Introduction}

Trunk pipelines that pass through tectonically active areas connecting oilfields and natural gas fields with terminals and refineries may cross active faults that can produce large earthquakes. Besides strong motion affecting vast areas, such earthquakes are often associated with surface faulting that provides additional hazard to pipelines. To avoid significant economic losses and environmental pollution, pipelines should be designed to sustain both effects - shaking and direct rupturing - without pipe damage and spill. The most well-known case study is the Alaska oil pipeline that withstood almost 6-m lateral offset during the 2002 Denali earthquake (Haeussler et al., 2004). Special studies aimed to provide necessary input data for the designers should be performed in the course of the engineering survey. Their scope is determined by special guidelines and national construction codes (Honegger and Nyman, 2004; American Lifelines Alliance, 2005; Indian Institute of Technology Kanpur, 2007).

Correspondence to: A. L. Strom (a.strom@g23.relcom.ru)
However, our experience on conducting and review of such studies for several oil and gas trunk pipelines in Russia show an urgent need for a stricter definition of basic conceptions and approaches used for identification and localisation of these potentially hazardous tectonic features.

\section{2 "Causative faults" - tectonically active structures determining seismic sources localisation}

The dual nature of hazard associated with active faults shaking affecting vast areas on the one hand and localised fault displacements on the other hand - determines the basic criteria of these geological structures' identification and of their spatial localisation accuracy. The character of forces affecting the pipeline and possible protection measures should be considered as a starting point for further analysis.

In the case of strong motion caused by seismic waves that may affect dozens of kilometres of pipeline route, we deal with "causative faults" - neotectonic structures with which sources of shallow-focus earthquakes are associated. Causative faults can be identified using both direct and indirect evidence of Late Pleistocene - Holocene activity. Sometimes, when a causative fault is marked by surface ruptures of recent and/or past earthquakes, it can be defined as a real "active fault". However, although in some regions (Japan, California, North Anatolian fault zone in Turkey, Mongolia, Iran, etc.) most of the shallow focus earthquakes have produced surface faulting along their causative faults, a significant number of large $(M>6.5)$ earthquakes world-wide has not been associated with such geological features. Thus, in many regions, in particular, in the remote parts of Russia with limited historical records of natural phenomena and densely forested terrain, causative faults could be mainly delineated by use of indirect evidence of recent tectonic activity. This can be exemplified by the seismic hazard assessment

Published by Copernicus Publications on behalf of the European Geosciences Union. 


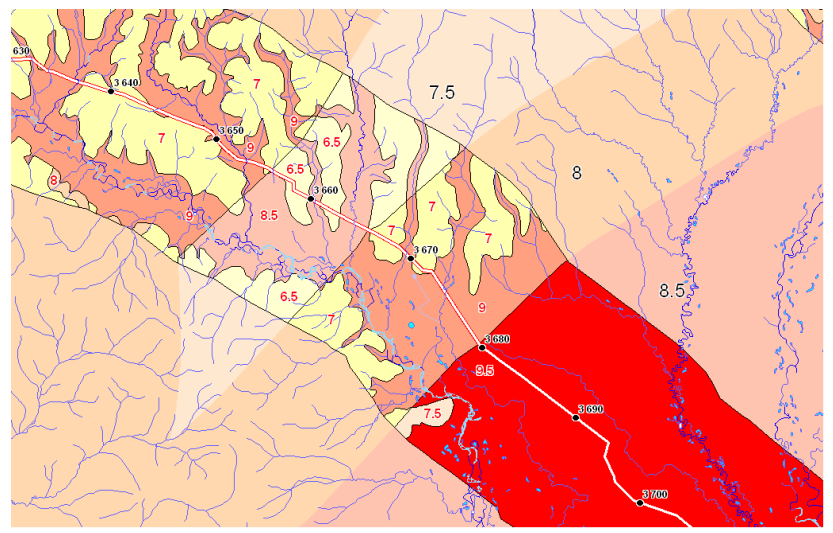

Fig. 1. Fragment of the detailed seismic zoning map of the trunk pipeline route in the Far East of Russia. The pale colours with large black numbers - background seismic intensity calculated according to the causative faults position (in points of the MSK-64 scale, with 0.5 point step); brighter colours with red numbers within the narrower corridor - seismic intensity specified according to the local soil conditions.

performed for the second stage of the Eastern Siberia - Pacific trunk oil pipeline. It crosses numerous large fault zones, none of which, however, features real evidence of recent surface faulting. Causative fault zones have been selected, based on their general topographic expression (significant linear steps in the relief), the presence of low magnitude earthquakes, data on strong earthquakes in Chinese territory whose epicentres coincide with the southward extension of the studied faults, etc. Unfortunately, no data on the orientation of either the axis of aftershock area or of the area of highest intensity of these earthquakes are available. Such data, if it were available, could tell much more about the position and orientation of the causative fault than the epicentre of the main shock itself. Nevertheless, the data collected has allowed delineating possible causative faults, which are likely to produce earthquakes with magnitudes ranging from 5.5 to 7.0 .

It should be pointed out that use of indirect criteria for causative fault identification allows for an accuracy of its location up to $\pm 1-2 \mathrm{~km}$ only. However, since strong motion parameters are almost constant within the near-field zone, whose width in case of large earthquake is up to dozens kilometres (Aptikaev, 2001), the low accuracy of active fault location is not so critical and can be considered as acceptable for seismic hazard assessment. Based on the set of source zones, the pipeline route zoning could be performed either in terms of intensity (in MM or EMS or MSK-64 points) and peak acceleration, or in terms of $A \times T$ - product of peak acceleration and prevailing vibration period, which is used for calculation of longitudinal stress in the pipe (SNiP 2.05.06.85*, 1996, item 8.57).

Consideration of the local soil conditions along the pipeline route allows its further detailed seismic zoning, of

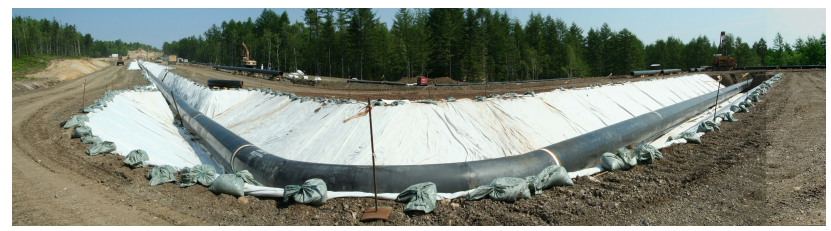

Fig. 2. Construction of the dog-leg structure at the trunk pipeline/active fault crossing at Sakhalin. Photo courtesy Oksana Golubtsova.

which an example is shown on Fig. 1, and also the selection of areas prone to liquefaction.

\section{Basic criteria of "active faults" identification and their localisation accuracy}

Another hazardous effect of earthquakes posing a significant threat to pipelines is surface rupturing that can result in direct cutting of pipes, especially if the latter are buried. A special rupture-proof design of the endangered pipeline sections (Fig. 2) requires much more precise localisation of the potentially hazardous active fault, assessment of the design displacement value and kinematics (Strom et al., 2009).

In such cases, a low accuracy of active fault localisation, admissible for causative faults described above, is completely unacceptable. The position of the potentially rupturing fault must be localised as precisely as possible, with an accuracy no less than $\pm 20-25 \mathrm{~m}$ (Mattiozzi and Strom, 2008), which may be up to $\pm 50 \mathrm{~m}$ as an extremity. Such fault location accuracy can be provided by use of the direct evidence of fault recent activity (traces of surface faults displacing Late Pleistocene-Holocene sediments and/or geomorphic features of the same age) only. Besides, data on the offset value and direction (kinematics) can solely be derived with relevant accuracy from the data on past rupturing events. Methods of field studies that should be carried out to obtain these data are summarised in McCalpin (2009).

The use of direct evidence of fault activity allows discrimination of really hazardous features (Fig. 3) that require special measures to ensure pipeline safety among numerous geological faults that cross pipeline routes hundreds to thousands of kilometres long. Otherwise pipelines in tectonically active regions, such as an Alpine belt, Sakhalin or Kamchatka would be composed entirely of the specially designed sections with compensators and special pipes, which would make them economically inadmissible.

\section{4 “Active faults" concept versus "Geodynamically active zones" concept}

In Russian scientific literature, along with an "Active Fault" concept a concept of the "Geodynamically Active Zone" ("GAZ") is widely used. These zones are defined as "zones 


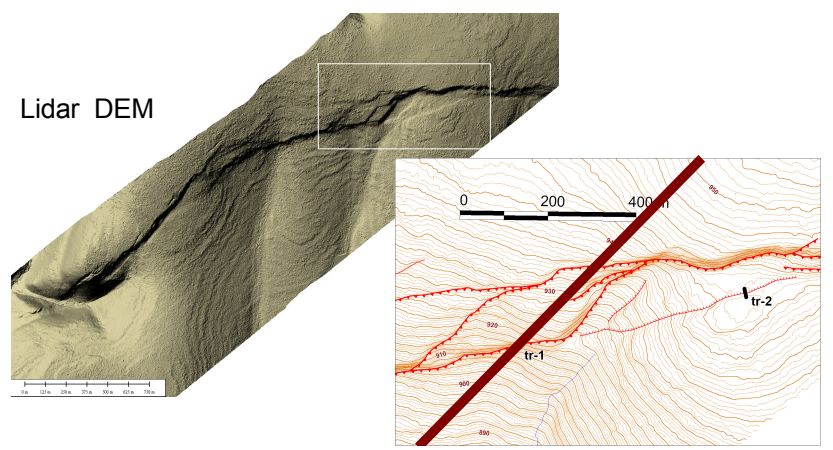

Fig. 3. Crossing of the trunk pipeline by the Chulmakan active fault (Southern Yakutia). LIDAR DEM hillshade image (above) and detailed topography of the outlined fragment (bellow). The presence of such a feature crossing the route requires a special design of the endangered pipeline section.

of recent (modern) tectonic activity", often related to the buried fault zones, especially in the platform areas (e.g. Makarov et al., 2007; Voeikova et al., 2007). However, both definition of the Geodynamically Active Zone, and the criteria of their localisation are formulated too broadly. For example, Makarov et al. (2007) define GAZ at the tectonic platforms as: "spatially localised linear or isometric parts (areas) of the earth crust of different scales where conditions favourable to concentration and release of tectonic stress, high gradients of movements and rock deformations exist or may arise due to various reasons".

We believe that from a practical point of view, the delineation of potentially hazardous zones without a clear and distinct definition of an exact hazardous factor(s) is almost useless. Such a broad concept of the GAZ as of "something hazardous" does not allow engineers to make a decision on how to protect from this "hazard", in order to avoid or minimise negative consequences. It is especially important for such linear structures as trunk pipelines and other lifelines that, due to any reasons, cannot bypass the suspicious zone and have to cross it. If, for example, we assume any geodynamically active zone (fault) as being excessively permeable due to "high gradients of movements", where the pipeline could be affected by some corrosive fluids, possible options to protect the pipe from the corrosion could include: (1) use of less corrodible pipe steel, (2) use pipes with thicker wall and with thicker and more resistant pipe isolation, (3) crossing of the zone at a right angle to make the affected pipeline section shorter. If, however, the hazard would be related to mechanical deformation due to surface faulting, then (1) pipe steel should be more ductile, (2) trench should be trapezoid in shape with special backfill material and (3) crossing angle should not be right (dog-leg crossing) to avoid pipe longitudinal compression (Honegger and Nyman, 2004; Mattiozzi and Strom, 2008). One can see that these measures are not only different (No. 1 and 2), but, moreover, they could be quite contrary to each other (No. 3).
Following design engineers - end-users of the data, provided by seismotectonic studies, we assert that "no quantity - no hazard". This is true both for shaking-proof and for rupture-resistant structure design and should be considered as a mandatory requirement in active fault studies performed as a part of pipeline route engineering investigations.

In contrast, the "Active Fault" concept implies the mechanical displacement of adjoining blocks of Earth's crust divided by this fault as a hazardous factor with a clearly defined width, kinematics and offset value or rate, thus providing required quantitative characteristics of hazard. Those faults crossing pipeline routes should be classified as active, which single-event displacement (or cumulative displacement during pipeline lifetime) can affect pipes mechanically in such a way that it would require a special design of the pipeline section to protect it from damage and spill. Possible displacements should exceed typical thermally or hydrodynamically induced movements of a pipeline anticipated by "standard" design measures. Only those faults characterised by such parameters should be selected as the output of seismotectonic investigations performed in the course of the trunk pipeline routes engineering survey. A fault capable of mm-cm offset would not be identified therefore as an active $=$ hazardous one. It should be strictly pointed out, however, that for other types of structures, like nuclear power plants, or factories with precise machinery, the threshold value of this parameter (offset value) would be different.

\section{Conclusions}

The design of seismically resistant pipelines requires quantitative assessment of all parameters determining pipeaffecting forces, both in cases of seismic shaking and of direct rupturing. Besides, the accuracy of these parameters assessment should correspond to the design requirements and to the physical nature of earthquake effects posing a threat to the pipeline and its associated facilities. The assessment of seismic strong motion hazard requires only rather low accuracy of causative faults' localisation (provided by indirect evidence of fault activity). In contrast, the relevant accuracy of localisation and characterisation of active faults, capable of surface rupturing affecting the pipeline directly, can be achieved solely by the use of direct evidence of fault activity.

It should be strictly defined in Russian regulations (construction codes and guidelines), which must be elaborated with regard to world-wide best practice and most detailed foreign construction codes. The necessity of such regulations is evident, considering the intensive development of new oil and natural gas fields in seismically active regions of Russia. We assume that it should be of current importance for other countries of the former Soviet Union as well.

Acknowledgements. The authors thank their colleagues

Andrey Kozhurin, Valery Imaev and Vladimir Makeev for useful discussions. 
Edited by: E. Krausmann

Reviewed by: two anonymous referees

\section{References}

American Lifelines Alliance: Guidelines for Assessing the Performance of Oil and Natural Gas Pipeline Systems in Natural Hazard and Human Threat Events, 2005.

Aptikaev, F. F.: Seismic strong motion (seismic effects), Doctor of Science dissertation, Moscow, Institute of Physics of Earth, 2001.

Haeussler, P. J., Schwartz, D. P., Dawson, T. E., Stenner, H. D., Lienkaemper, J. J., Sherrod, B., Cinti, F. R., Montone, P., Craw, P. A., Crone, A. J., and Personius, S. F.: Surface Rupture and Slip Distribution of the Denali and Totschunda Faults in the 3 November 2002 M 7.9 Earthquake, Alaska, Bull. Seismol. Society of America, 94(6B), 23-52, 2004.

Honegger, D. G. and Nyman, D. J.: Guidelines for the seismic design and assessment of natural gas and liquid hydrocarbon pipelines, 2004.

Indian Institute of Technology Kanpur: Guidelines for Seismic Design of Buried Pipelines, 2007.
Makarov, V. I., Dorozhko, A. L., Makarova, N. V., and Makeev, V. M.: Modern geodynamically active zones in platforms. Geoecology, Engineering Geology, Hydrogeology, Geocryology, 2, 99110, 2007.

Mattiozzi, P. and Strom, A.: Crossing Active Faults on the Sakhalin II Onshore Pipeline Route: Pipeline Design and Risk Analysis. Proceedings of Seismic Engineering Conference Commemorating ttie 1908 Messina and Reggio Calabria Earthquake, edited by: Santini, A. and Moraci, N., American Institute of Physics, 1004-1013, 2008.

McCalpin, J. P. (Ed.): Paleoseismology. Second edition. International Geophysical Series, Vol. 95, Elsevier, 2009.

SNiP 2.05.06.85*: Russian State Construction Code "Trunk pipelines", 1996.

Strom, A., Ivaschenko, A., and Kozhurin, A.: Assessment of the Design Displacement Values at Seismic Fault Crossings and of their Excess Probability, in: Geological Engineering Problems in Major Construction Projects, edited by: Huang, R., Rengers, N., Li, Z., and Tang, C., Proc. 7th Asian Regional Conf. of IAEG, 9-11 September 2009, Chengdu, China, 2009.

Voeikova, O. A., Makarov, V. I., and Nesmeyanov, S. A.: Study of the newest near-surface faults in platforms upon the engineering survey. Geoecology, Engineering Geology, Hydrogeology, Geocryology, No 3, 267-280, 2007. 